Nonetheless, this paper is important because it adds to the body of evidence that early cessation of exposure improves the outcome in occupational asthma. It is well known that the likelihood of improvement or resolution of symptoms or of preventing deterioration is greater in workers who have no further exposure to the causative agent. ${ }^{3}$ It is also known that the likelihood of improvement or resolution of symptoms or of preventing deterioration is greater in workers who have shorter duration of symptoms before avoidance of exposure. ${ }^{3}$ Symptoms and non-specific bronchial hyperresponsiveness (BHR) to methacholine can persist for 10 years after removal from exposure in patients with occupational asthma caused by toluene di-isocyanate. ${ }^{13}$ A more favourable prognosis was associated with less BHR at the time of diagnosis. ${ }^{13}$

Pharmacological management of occupational asthma is similar to nonoccupational asthma. The observational study by Anees et al did not detect a benefit on $\mathrm{FEV}_{1}$ from inhaled steroids. ${ }^{12}$ However, a randomised controlled crossover trial of inhaled beclomethasone $1000 \mu \mathrm{g} /$ day found small effects on symptoms, peak flow, and quality of life in patients with occupational asthma. ${ }^{14}$ The beneficial effects were more pronounced if steroids were given early after diagnosis. Another small cohort study found that the same dose of inhaled steroid together with long acting bronchodilators seemed to prevent deterioration over 3 years among workers with mild to moderate occupational asthma who were still exposed to the causal agent. ${ }^{15}$

The paper by Anees and colleagues ${ }^{12}$ provides further support that patients with occupational asthma should be removed from further exposure to the causal agent as soon as the diagnosis is confirmed. This may require retraining and/or alternative duties. Early cessation of exposure will improve symptoms and avoid the excessive loss of lung function that could result in earlier onset of respiratory disability. There is a place for treatment with inhaled steroids and long acting bronchodilators, but this should not be at the expense of continuing exposure, cessation of which must be the first line of management.

There is a pressing need for better evidence from randomised controlled trials of both pharmacological and non-pharmacological management of patients with occupational asthma. Effective health surveillance of exposed workers and early detection and removal of affected workers should be an essential aim for governments and practitioners concerned with the prevention of this important cause of occupational disease.

Thorax 2006;61:741-742.

doi: $10.1136 /$ thx. 2005.056200

\section{Authors' affiliations}

M J Abramson, Department of Epidemiology and Preventive Medicine, Monash University, Melbourne, Australia

M R Sim, Centre for Occupational and

Environmental Health, Department of

Epidemiology and Preventive Medicine,

Monash University, Melbourne, Australia

Correspondence to: Professor M J Abramson Department of Epidemiology and Preventive Medicine, Central and Eastern Clinical School, The Alfred Hospital, Melbourne, Victoria 3004 Australia; Michael.Abramson@med.monash. edu.au

Competing interests: none declared.

\section{REFERENCES}

1 Meyer JD, Holt DL, Chen Y, et al. SWORD '99: surveillance of work-related and occupational respiratory disease in the UK. Occup Med 2001:51:204-8.

2 Elder D, Abramson M, Fish D, et al. Surveillance of Australian workplace Based Respiratory Events (SABRE): notifications for the first 3.5 years and validation of occupational asthma cases. Occup Med 2004;54:395-9.

3 Newman Taylor AJ, Nicholson PJ, Cullinan P, etal. Guidelines for the prevention, identification and management of occupational asthma: evidence review and recommendations. London, British Occupational Health Research Foundation, 2004, http://www.bohrf.org.uk/content/asthma.htm.

4 Mapp CE, Boschetto P, Maestrelli P, et al. Occupational asthma. Am J Respir Crit Care Med 2005:172:280-305.

5 Hnizdo E, Esterhuizen TM, Rees D, et al. Occupational asthma as identified by the Surveillance of Work-related and Occupational Respiratory Diseases programme in South Africa. Clin Exp Allergy 2001;31:32-9.

6 Karjalainen A, Kurppa K, Virtanen S, etal. Incidence of occupational asthma by occupation and industry in Finland. Am J Ind Med 2000;37:451-8.

7 American Thoracic Society. Occupational contribution to the burden of airway disease. Am J Respir Crit Care Med 2003;167:787-97.

8 Leigh JP, Romano PS, Schenker MB, et al. Costs of occupational COPD and asthma. Chest 2002; 121:264-72

9 Sim MR. The continuing challenge to reduce the burden of occupational asthma. What is the best approach? Occup Environ Med 2003;60:713-4.

10 LaMontagne AD, Radi S, Elder D, et al. Primary prevention of latex-related sensitisation and occupational asthma: a systematic review. Occup Environ Med 2006;63:359-64.

11 Blanc PD, Burney $P$, Janson $C$, et al. The prevalence and predictors of respiratory-related work limitation and occupational disability in an international study. Chest 2003; 124:1 153-9.

12 Anees W, Moore VC, Burge PS. FEV 1 decline in occupational asthma. Thorax 2006;61:751-5.

13 Padoan M, Pozzato V, Simoni M, et al. Long-term follow-up of toluene diisocyanate-induced asthma. Eur Respir J 2003;21:637-40.

14 Malo J, Cartier A, Cote J, et al. Influence of inhaled steroids on recovery from occupational asthma after cessation of exposure: an 18 month double-blind crossover study. Am J Respir Crit Care Med 1996;153:953-60.

15 Marabini A, Siracusa A, Stopponi R, et al. Outcome of occupational asthma in patients with continuous exposure: a 3-year longitudinal study during pharmacologic treatment. Chest 2003; 124:2372-6.

\title{
Theophylline for COPD
}

\section{P J Barnes}

\section{Reinstatement in the light of new evidence?}

$\mathrm{T}$ heophylline has been used as a bronchodilator in the treatment of COPD for over 70 years, but has lost popularity as better tolerated and more effective bronchodilators have been introduced. However, new insights into the molecular action of theophylline have raised the possibility that this old drug may come back into favour as an anti-inflammatory treatment and may even reverse steroid resistance in COPD. ${ }^{1}$ A paper by Hirano et al in this issue of Thorax provides further support for the anti-inflammatory effects of theophylline in patients with COPD. $^{2}$

\section{CURRENT USE OF THEOPHYLLINE IN COPD}

In the major guidelines for the treatment of COPD, theophylline is relegated to a third line bronchodilator after inhaled anticholinergics and $\beta_{2}$ agonists. Nevertheless, it is recognised that theophylline is a useful treatment in patients with severe COPD as its withdrawal leads to significant clinical worsening of the disease. ${ }^{3}$ Many older clinicians have been convinced by its clinical value in severe disease.

\section{THEOPHYLLINE AS A BRONCHODILATOR}

Traditionally, theophylline was used as a bronchodilator in the treatment of airway disease but, to achieve significant bronchodilatation comparable with 
that of a $\beta_{2}$ agonist, relatively high plasma concentrations are needed ( 10 $20 \mathrm{mg} / \mathrm{l}$ ). Theophylline relaxes human airway smooth muscle in vitro through inhibition of phosphodiesterases (PDE), enzymes that break down cyclic nucleotides in the cell resulting in increased cyclic AMP concentrations. Unfortunately, at doses of theophylline that inhibit PDE, side effects that are also due to PDE inhibition are common so many patients are not able to tolerate theophylline at these "therapeutic" concentrations.

\section{NON-BRONCHODILATOR EFFECTS}

Many patients appear to derive clinical benefit from theophylline at doses that give a plasma concentration well below that needed for bronchodilatation. This suggests that theophylline must have some additional beneficial effect, and this is exemplified by the worsening of disease control when theophylline is withdrawn. ${ }^{3}$ There is now good evidence for inhibitory effects of theophylline on airway inflammation in COPD, and these effects are seen at plasma concentrations below $10 \mathrm{mg} / \mathrm{l}^{45}$ This is particularly striking as corticosteroids have no demonstrable anti-inflammatory effects on the same parameters, even at high doses. These data are now confirmed by Hirano et $a l^{2}$ who have confirmed that a low dose of theophylline significantly reduces sputum neutrophils.

\section{MECHANISMS OF ANTI- INFLAMMATORY EFFECTS}

Many different mechanisms have been proposed for the anti-inflammatory effects of theophylline, but none of these can account for the effects of low doses of theophylline that are effective clinically as high concentrations are needed to demonstrate these actions in vitro. ${ }^{6}$ However, these mechanisms can account for all of the side effects of theophylline. PDE inhibition accounts for nausea, vomiting, headaches and diuresis, whereas adenosine receptor antagonism explains the cardiac arrhythmias and seizures that occur with very high plasma concentrations. These mechanisms cannot account for the clinical effects of low doses of theophylline, and this indicates that there must be some other mechanism responsible for its anti-inflammatory effects.

\section{HISTONE DEACETYLASE ACTIVATION}

Expression of inflammatory genes is regulated by the balance between histone acetylation and deacetylation. ${ }^{7}$ In COPD a number of inflammatory genes are activated through pro-inflammatory transcription factors such as nuclear factor- $\kappa \mathrm{B}(\mathrm{NF}-\kappa \mathrm{B})$, which leads to histone acetylation and increased transcription. This process is reversed by the recruitment of histone deacetylases (HDAC) to the activated inflammatory gene promoter site within the nucleus. We have previously shown that corticosteroids suppress inflammation by recruiting HDAC2 to activated inflammatory genes, thus switching off their expression. This molecular mechanism is defective in COPD patients as HDAC2 activity and expression is markedly reduced, thus accounting for the steroid resistance of COPD. ${ }^{8}$ We have shown that theophylline is an activator of HDACs and enhances the anti-inflammatory effect of corticosteroids, as well as reversing steroid resistance in cells from COPD patients. ${ }^{9}{ }^{10}$ This action of theophylline is seen at low plasma concentrations (optimally $5 \mathrm{mg} / \mathrm{l}$ ) and is independent of PDE inhibition and adenosine antagonism. The effect of theophylline is completely blocked by an HDAC inhibitor called trichostatin A and by knocking out HDAC2 using interference RNA. $^{11}$ The reason why theophylline selectively activates HDAC activity is not yet known, but appears to be indirect through the activation of kinase and phosphatase pathways in the cell.

\section{ROLE OF OXIDATIVE AND NITRATIVE STRESS}

We have proposed that the defect in HDAC2 function and expression that is seen in COPD cells and lungs is the result of increased oxidative and nitrative stress. ${ }^{12}$ Reactive oxygen species and nitric oxide generated from inducible nitric oxide synthase avidly interact to form peroxynitrite, an unstable radical that may nitrate tyrosine residues in proteins to alter their function and stimulate its enzymatic destruction. HDAC2 in COPD lungs shows excessive nitration and this is associated with reduced HDAC activity. ${ }^{13}$ Hirano and colleagues now show that theophylline significantly reduces the concentrations of 3-nitrotyrosine, the stable product of peroxynitrite, which is raised in sputum cells of COPD patients. ${ }^{214}$ By contrast, an inhaled corticosteroid had little effect. This suggests that theophylline might restore HDAC activity in two ways: through activation of the enzyme as described above and through reduction in tyrosine nitration of the enzyme, thus increasing HDAC activity in COPD patients. This would have an antiinflammatory action in its own right but, of more importance, may reverse the resistance to the anti-inflammatory effects of corticosteroids. A clinical trial to explore whether low dose theophylline restores corticosteroid responsiveness in COPD is currently underway.

\section{CLINICAL IMPLICATIONS}

It is predicted from the in vitro studies in COPD cells and (unpublished) animal studies that low dose theophylline (giving a plasma concentration of $\sim 5 \mathrm{mg} / \mathrm{l}$ ) will reverse steroid resistance in COPD patients and thus control inflammation. Theophylline may have a unique effect in the treatment of COPD by restoring reduced HDAC activity to normal levels, thus suppressing inflammation but also potentially making the patients responsive to corticosteroids. If this is correct this should improve symptoms, reduce exacerbations, and reduce the progression of the disease. Furthermore, at these low doses of theophylline, side effects are not a problem. Moreover, this treatment would be relatively cheap and may be an appropriate approach to the global epidemic of COPD, although not popular with major pharmaceutical companies. Perhaps theophylline will be reinstated in the future when long term clinical trials have been completed.

If the signal transduction pathways responsible for HDAC activation by theophylline can be defined, this might lead to the development of new antiinflammatory therapies that are completely free of the side effects seen with high doses of theophylline, providing a novel therapeutic approach to COPD.

Thorax 2006:61:742-744.

doi: 10.1136/thx.2006.061002

Correspondence to: Professor Peter J Barnes, National Heart \& Lung Institute, Imperial College London, Dovehouse Street, London SW3 6LY, UK; p.j.barnes@imperial.ac.uk Competing interests: none declared.

\section{REFERENCES}

1 Barnes PJ. Theophylline in chronic obstructive pulmonary disease: new horizons. Proc $\mathrm{Am}$ Thorac Soc 2005;2:334-9.

2 Hirano T, Yamagata T, Gohda M, et al. Inhibition of reactive nitrogen species production in COPD airways: comparison between inhaled corticosteroid and oral theophylline. Thorax 2006;61:761-6.

3 Kirsten DK, Wegner RE, Jorres RA, et al. Effects of theophylline withdrawal in severe chronic obstructive pulmonary disease. Chest 1993; 104:1101-7.

4 Culpitt SV, de Matos C, Russell RE, et al. Effect of theophylline on induced sputum inflammatory indices and neutrophil chemotaxis in COPD. Am J Respir Crit Care Med 2002; 165:1371-6.

5 Kobayashi M, Nasuhara Y, Betsuyaku T, et al. Effect of low-dose theophylline on airway inflammation in COPD. Respirology 2004;9:249-54

6 Barnes PJ. Theophylline: new perspectives on an old drug. Am J Respir Crit Care Med 2003;167:813-8.

7 Barnes PJ, Adcock IM, Ito K. Histone acetylation and deacetylation: importance in inflammatory lung diseases. Eur Respir J 2005;25:552-63.

8 Ito $\mathrm{K}$, Ito $M$, Elliott WM, et al. Decreased histone deacetylase activity in chronic obstructive 
pulmonary disease. N Engl I Med 2005;352:1967-76.

9 Ito K, Lim S, Caramori G, et al. A molecular mechanism of action of theophylline: induction of histone deacetylase activity to decrease inflammatory gene expression. Proc Natl Acad Sci USA 2002;99:8921-6.

10 Cosio BG, Tsaprouni L, Ito K, et al. Theophylline restores histone deacetylase activity and steroid responses in COPD macrophages. J Exp Med 2004;200:689-95.

11 Ito K, Yamamura S, Essilfie-Quaye S, et al. Histone deacetylase 2-mediated deacetylation of the glucocorticoid receptor enables NF- $\mathrm{KB}$ suppression. J Exp Med 2006;203:7-13.

12 Barnes PJ, lto K, Adcock IM. A mechanism of corticosteroid resistance in COPD: inactivation of histone deacetylase. Lancet 2004;363:731-3.
13 Ito K, Tomita T, Barnes PJ, et al. Oxidative stress reduces histone deacetylase (HDAC) 2 activity and enhances IL-8 gene expression: role of tyrosine nitration. Biochem Biophys Res Commun 2004;315:240-5.

14 Ichinose M, Sugiura H, Yamagata S, et al. Increase in reactive nitrogen species production in chronic obstructive pulmonary disease airways. Am J Respir Crit Care Med 2000;160:701-6.

\section{Standardisation of lung function} testing: helpful guidance from the ATS/ERS Task Force

\section{G Laszlo}

\section{A critical overview of the new ATS/ERS guidelines}

$\mathrm{T}$ he American Thoracic Society and the European Respiratory Society have jointly issued a new revision of their guidelines for the performance of spirometry, lung volumes, and carbon monoxide transfer factor. These have been published as a series of documents in the European Respiratory Journal. ${ }^{1-5}$ They contain much wisdom, some compromises, and a few new recommendations. Blood gases, sleep, exercise, and challenge testing have not yet been readdressed. This brief review highlights a few of the more important recommendations dealing with the performance and interpretation of the several tests.

\section{GENERAL CONSIDERATIONS}

This first chapter is essential reading for laboratory staff and sets standards for hygiene, calibration, quality control, and housekeeping. Observance of these standards will reassure research workers as well as clinicians.

\section{SPIROMETRY}

Peak flow is the topic of current research and the task force plans to introduce more stringent standards for home recording. It may be derived from the flow-volume plot or from a separate blow, ideally using a flow measuring device. The guideline emphasises the importance of rehearsal and the need to blow immediately after a full inspiration.

Relaxed expired and inspired vital capacity (EVC and IVC) have been rehabilitated, in spite of the fact that the various COPD guidelines-such as GOLD and others-chose to dispense with them for simplicity. When performing spirometry, the suggested method for EVC is to take the best of three measurements made before the forced expiratory tests, instructing the patient to speed the expiration only at the beginning and end of the blow. There is still no validated standard patter for this test; one suggestion might be "take a full breath in; breathe out gently but firmly", going on to further encouragement after 2-3 seconds until flow is less than $0.25 \mathrm{l} / \mathrm{s}$.

For forced vital capacity (FVC), the Working Party has retained the old ATS recommendation to record 14 seconds of forced expiration, using the same criterion to identify the end of the test, and emphasising the need to inspect the curves to identify glottal closure and other sources of error. The 6 second blow $\left(\mathrm{FEV}_{6}\right)$ is fully documented as a surrogate for the more demanding FVC manoeuvre, ${ }^{6}$ but the Task Force stopped short of recommending its use, perhaps because of the lack of European standards. This topic has been aired again since the guidelines were published..$^{7-9}$ $\mathrm{FEV}_{1} / \mathrm{FEV}_{6}$ identifies $94 \%$ of those diagnosed as having airflow obstruction by $\mathrm{FEV}_{\mathrm{l}} / \mathrm{FVC}$ using normal values for the latter. The only obstacle to replacing FVC is the lack of well documented reference data from Europe; crudely, $\mathrm{FEV}_{\mathrm{l}} / \mathrm{FVC}<0.7$ identifies the same population as $\mathrm{FEV}_{1} / \mathrm{FEV}_{6}<0.73$. $^{7}$

Vital capacity (VC) is defined in the document as the maximal volume that can be displaced from the lung-that is, the greatest among EVC, FVC and IVC. EVC can be greater or less than FVC in healthy subjects and those with restrictive ventilatory disorders, according to the method used; EVC usually exceeds
FVC in patients with COPD. For identifying airflow obstruction it would therefore make sense to abandon the 14 second $\mathrm{FVC}$, measure $\mathrm{FEV}_{1}$ as a fraction of $\mathrm{FEV}_{6}$, EVC and IVC, and report the lowest of these ratios as $\mathrm{FEV}_{1} / \mathrm{VC}$.

Numerous examples of characteristic flow-volume loops are provided; it is implied that their appearance is much more informative than numerical indices derived from them. The latter are dismissed without any description or references because it is said that all the clinical information they contain can be derived from $\mathrm{FEV}_{1}, \mathrm{VC}, \mathrm{PEF}$, and $\mathrm{FEF}_{25}$ 75. $\mathrm{FEF}_{25}$ is the approved term to describe the instantaneous flow when $25 \%$ of the FVC has been exhaled. Standards are set for equipment and there are some suggestions about the sequence of blows.

\section{LUNG VOLUMES}

This section reflects the wide range of practice. Body plethysmography is described first, then nitrogen washout (which persists because of the useful indices of gas mixing such as lung clearance index that can be calculated as well), and then helium dilution. No great change is recommended. Regarding plethysmography, it is recommended that the term thoracic gas volume (TGV) should be abandoned and replaced by functional residual capacity (FRC), which implies that the operator will have to train the subject not to breathe in while waiting for the shutter to close.

There was no consensus about whether to breathe in or out first from FRC when measuring the subdivisions of lung volume; one of each would be a sensible compromise. Breathing to residual volume (RV) first followed by IVC gives a good estimate of both RV and total lung capacity (TLC), which can be compared with single breath RV and alveolar volume measured with the same manoeuvre during the measurement of carbon monoxide transfer factor (TLCO).

Rebreathing of helium is regarded as complete when the helium concentration falls by less than $0.02 \%$ in 30 seconds, the time to achieve this being "rarely longer than 10 minutes". Being sufficiently reproducible, one technically satisfactory 